\title{
Article
}

\section{Intraoperative Assessment of Coronary Resistances: A New Quality Marker and Potential Tool to Predict Early Graft Failure after Coronary Artery Bypass Grafting?}

\author{
Antonino Salvatore Rubino*D, Fabrizio Ceresa, Liborio Mammana, Giuseppe Vite, Gianluca Cullurà, \\ Augusto Palermo, Aurora Leonardi, Bruna Filomena De Donno and Francesco Patanè
}

check for updates

Citation: Rubino, A.S.; Ceresa, F.; Mammana, L.; Vite, G.; Cullurà, G.; Palermo, A.; Leonardi, A.; De Donno, B.F.; Patanè, F. Intraoperative Assessment of Coronary Resistances: A New Quality Marker and Potential Tool to Predict Early Graft Failure after Coronary Artery Bypass Grafting? J. Cardiovasc. Dev. Dis. 2021, 8, 163. https://doi.org/ $10.3390 /$ jcdd 8120163

Academic Editors: Kenya Kusunose and Michele Di Mauro

Received: 3 October 2021

Accepted: 23 November 2021

Published: 26 November 2021

Publisher's Note: MDPI stays neutral with regard to jurisdictional claims in published maps and institutional affiliations.

Copyright: (c) 2021 by the authors. Licensee MDPI, Basel, Switzerland. This article is an open access article distributed under the terms and conditions of the Creative Commons Attribution (CC BY) license (https:/ / creativecommons.org/licenses/by/ $4.0 /)$.
Division of Cardiac Surgery, Department of Cardio-Thoraco-Vascular Surgery, Papardo Hospital, 98158 Messina, Italy; fabrizioceresa@aopapardo.it (F.C.); liboriomammana@aopapardo.it (L.M.); giuseppevite@aopapardo.it (G.V.); gianlucacullura@aopapardo.it (G.C.); augustopalermo@aopapardo.it (A.P.); auroraleonardi@aopapardo.it (A.L.); brunadedonno@aopapardo.it (B.F.D.D.); francescopatane@aopapardo.it (F.P.)

* Correspondence: antonio.rubino@hotmail.com; Tel.: +39-090-3991

\begin{abstract}
Intraoperative assessment of graft patency is pivotal for successful coronary revascularization. In the present study we aimed to propose a new, easy to perform tool to assess anastomotic quality intraoperatively, and to investigate its potential reliability in predicting early graft failure. Intraoperative graft flowmetry of 63 consecutive patients undergoing CABG were prospectively collected. Transit time flowmetry and its derivatives were recorded. Coronary resistances were calculated according to Hagen-Poiseuille equation both during cardioplegic arrest and after withdrawal from cardiopulmonary bypass. Angiographic evidence of graft occlusion at follow-up was cross-checked with intraoperative recordings. After a mean follow-up of $10.4 \pm 6.0$ months, 22 grafts were studied, and occlusion was documented in five (22.7\%). Occluded grafts showed lower flows and higher resistances recorded during aortic cross-clamping. Coronary resistances, recorded during aortic cross-clamping, greater than $2.0 \mathrm{mmHg} / \mathrm{mL} / \mathrm{min}$, showed a sensitivity of $80 \%$ and a specificity of $100 \%$ to predict graft failure. We propose the routine recording of coronary resistances during aortic cross-clamping as an additional tool to overcome the acknowledged limitation of TTF to predict graft occlusion at 1 year.
\end{abstract}

Keywords: coronary artery bypass graft; coronary resistances; transit-time flowmetry

\section{Introduction}

Intraoperative assessment of graft patency is pivotal for successful coronary revascularization. As early graft failure is usually consequential to technical faults (e.g., graft twisting, stretching, kinking or anastomotic errors), current guidelines suggest transit-time flow (TTF) measurements to assess intraoperative graft patency [1].

Several studies have aimed to discriminate the most reliable cut-off for the many available TTF derived parameters, but no one has demonstrated a clear reliability to predict quality and long-term graft patency [2-4].

In 1999, Belboul and colleagues demonstrated that coronary vascular resistances can be calculated intraoperatively using TTF [5]. This methodology has already been validated, also employing IABP [6].

In the present study we aimed to propose a new, easy to perform tool to assess anastomotic quality intraoperatively and to investigate its potential reliability in predicting early graft failure.

\section{Materials and Methods \\ 2.1. Study Population and Inclusion Criteria}

This is a retrospective analysis of prospectively collected data. From December 2019 to April 2020, intraoperative graft flowmetry of all consecutive grafts were collected in an 
institutional ad-hoc database. Surgery has always been performed by the same experienced surgeons (FP, FC) on normothermic cardiopulmonary bypass with aortic cross-clamping an intermittent hyperkaliemic blood cardioplegia. Inclusion criteria for the present analysis were age $\geq 18$ years, on pump surgery with aortic cross-clamp, first-time surgery. Patients undergoing off-pump coronary revascularization, emergency procedures and in-hospital deaths were excluded. Sixty-four patients fulfilled the inclusion criteria. One patient $(1.6 \%)$ died of pneumonia during hospitalization and was thus excluded from the study. Accordingly, 63 consecutive patients were part of the present analysis, accounting for a total of 113 grafts. Informed consent for the operation and for subsequent follow-up for research purposes was obtained from each patient upon hospital admission. The study protocol conforms to the ethical guidelines of the 1975 Declaration of Helsinki.

\subsection{Graft Flowmetry and Coronary Resistances}

Graft function was assessed under stable hemodynamic conditions, generally at $30 \mathrm{~min}$ after protamine administration. Flowmetry of the grafts was performed with a transit-time flowmeter (Optima flow QC, Transonic Systems Inc., Ithaca, NY, USA). Different probe sizes $(1.5,2.0,2.5 \mathrm{~mm})$ were available to avoid distortion or compression of grafts. Mean flow $(\mathrm{mL} / \mathrm{min})$ and pulsatility index $(\mathrm{PI})$ were obtained directly from the flowmeter. Mean arterial and central venous pressures were recorded as well.

For the specific aim of this study, flow $(\mathrm{mL} / \mathrm{min})$ and pressure drop on the cardioplegic line during selective cardioplegia administration in the venous grafts has been recorded; for homogeneity of data collection, flows were recorded at a standardized pressure of $100 \mathrm{mmHg}$ (Figure 1). Left internal mammary artery to left anterior descending (LIMALAD) graft TTFs were also recorded during aortic cross-clamp.

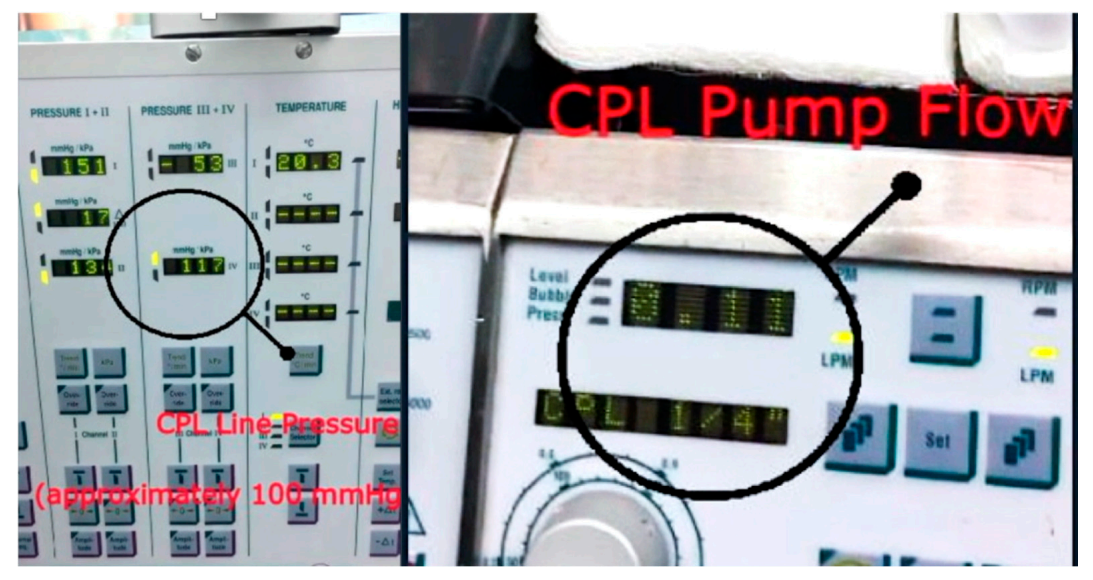

(a)

(b)

Figure 1. Examples of parameter estimates derived from cardiopulmonary bypass machine: (a) pressure drop on the cardioplegia line during selective administration in a venous graft; (b) amount of flow selectively delivered.

Coronary resistances $(\mathrm{CR})$ were calculated according to the Hagen-Poiseuille equation as $\mathrm{CR}=(\mathrm{P} 2-\mathrm{P} 1) / \mathrm{Q}$.

When CR were calculated after withdrawal from cardiopulmonary bypass, $\mathrm{P} 2$ is the mean arterial pressure in $\mathrm{mmHg}$, $\mathrm{P} 1$ is the central venous pressure in $\mathrm{mmHg}$, and $\mathrm{Q}$ is the mean flow (in $\mathrm{mL} / \mathrm{min}$ ) through the graft calculated during TTF analysis [5]. Transit-time flow (TTF) measurements were interpreted as previously reported [7].

When CR are calculated during aortic cross-clamping, differences should be made between venous and arterial grafts. Indeed, for venous grafts, P2 is the pressure drop in the cardioplegic line and $\mathrm{Q}$ is the flow of cardioplegia administered selectively in that graft; in the case of mammary artery grafts, $\mathrm{P} 2$ is the mean systemic perfusion pressure and $\mathrm{Q}$ is 
the mean flow recorded with TTF probes. In all these cases, P1 is considered equal to 0 , as all venous blood return is drained to the reservoir [5].

Angiographic data retrieved from patients undergoing coronary angiography during the first postoperative year, for onset of angina-like symptoms or instrumental signs of ischemia, were cross-checked with intraoperative flow recordings. A FizzGibbon grade greater than A was coded as angiographic occlusion.

\subsection{Endpoints of the Study}

The primary endpoints of this study were the assessment of the safety and technical feasibility to record intraoperative graft flow-derived parameters during aortic cross-clamp, as an alternative tool to beating heart transit-time flowmetry. The secondary endpoint was the identification of appropriate cut-off values to predict early graft failure during follow-up.

\subsection{Statistical Analyses}

Continuous variables are expressed as means and standard deviation, whereas categorical variables are reported as counts and percentages.

Differences in flow-derived parameters between occluded and patent grafts were assessed with an independent sample $t$-test, Mann-Whitney $U$ test and chi-square test.

The univariate association between CR-cardioplegia, CR-protamine, mean flow (included in the model either as a continuous variable or with predetermined cut-offs of $<20 \mathrm{~mL} / \mathrm{min}$ and $<31 \mathrm{~mL} / \mathrm{min}$ according to Queen [2] and Une [8], respectively) and pulsatility index $(\mathrm{PI})>3[2,9]$ with the angiographic evidence of graft occlusion at follow-up was investigated with logistic regression analysis. In case of quasi-complete separation, exact odds ratios and $95 \%$ confidence intervals have been computed.

The discriminant ability of the above-mentioned parameters was assessed, estimating the area under the receiver operating characteristic curve (AUC). An AUC $\geq 0.8$ was considered acceptable. For the specific purpose of our analysis, the DeLong test was used to determine if the differences between the AUCs were statistically significant from CR-cardioplegia [10]. The Youden index was used to identify the best cut-off values. The Bootstrap method with 10,000 resampling was implemented to compute $95 \%$ confidence intervals cut-offs, sensitivity, specificity [11].

All statistical analyses were performed using SAS version 9.4 statistical software (SAS Institute, Cary, NC, USA) and R version 3.6.1 (The R Foundation for Statistical Computing, Vienna, Austria) [12] with the cutpointr (version 1.0.1) package. Statistical significance was set at an alpha level of 0.05 .

\section{Results}

Baseline characteristics are listed in Table 1.

Table 1. Patients' characteristics.

\begin{tabular}{cc}
\hline Baseline & $n=63$ \\
\hline Age, years & $65.1 \pm 8.9$ \\
Female & $20(31.7)$ \\
Dypertension & $43(68.3)$ \\
Diabetes & $23(36.5)$ \\
COPD & $29(46.0)$ \\
Peripheral vascular disease & $11(17.5)$ \\
Creatinine >200 mmol/L & $10(15.9)$ \\
Dialysis & $4(6.3)$ \\
Prior myocardial infarction & $1(1.6)$ \\
Left main stem & $21(33.3)$ \\
LVEF & $39(61.9)$ \\
>50\% & \\
$<30 \%$ & $29(46.0)$ \\
<30 & $31(50.8)$ \\
Intraoperative Details & $2(3.2)$ \\
\hline Cardiopulmonary bypass time, min & $104.4 \pm 42.2$ \\
\hline COPD: chronic obstructive pulmonary disease; LVEF: left ventricular ejection fraction.
\end{tabular}




\subsection{Intraoperative Flow Measurements}

The mean number of grafts per patient was $2.3 \pm 1.2$. Flow-derived parameters, stratified per graft type and grafted territory are better described in Table 2. As a general rule of thumb, the equipoise between flows and pressures has been considered a quality marker of the coronary anastomosis (e.g., $\geq 100 \mathrm{~mL} / \mathrm{min}$ at $100 \mathrm{mmHg}$ for venous grafts [5]; a mean TTF flow at least equal to perfusion pressure for mammary artery grafts).

Table 2. Graft flowmetry and its derivatives stratified according to graft type and coronary territory.

\begin{tabular}{|c|c|}
\hline Flowmetry & Graft Type \\
\hline Parameter & SVG-Right coronary artery $(n=6)$ \\
\hline Flow during cardioplegia & $120.0 \pm 31.6$ \\
\hline CR cardioplegia & $0.84 \pm 0.19$ \\
\hline Mean TTF flow & $47.5 \pm 24.0$ \\
\hline CR TTF & $1.41 \pm 0.53$ \\
\hline PI & $1.4 \pm 0.6$ \\
\hline Parameter & SVG-Posterior descending artery $(n=8)$ \\
\hline Flow during cardioplegia & $98.8 \pm 14.6$ \\
\hline CR cardioplegia & $1.00 \pm 0.20$ \\
\hline Mean TTF flow & $35.5 \pm 19.7$ \\
\hline CR TTF & $2.83 \pm 4.26$ \\
\hline PI & $1.9 \pm 0.9$ \\
\hline Parameter & SVG-Obtuse Marginal $(n=38)$ \\
\hline Flow during cardioplegia & $104.5 \pm 32.4$ \\
\hline CR cardioplegia & $1.03 \pm 0.30$ \\
\hline Mean TTF flow & $39.2 \pm 21.4$ \\
\hline CR TTF & $1.94 \pm 1.43$ \\
\hline PI & $1.5 \pm 0.5$ \\
\hline Parameter & SVG-Ramus intermedius $(n=17)$ \\
\hline Flow during cardioplegia & $118.2 \pm 32.6$ \\
\hline CR cardioplegia & $0.89 \pm 0.23$ \\
\hline Mean TTF flow & $32.7 \pm 19.2$ \\
\hline CR TTF & $2.05 \pm 1.38$ \\
\hline PI & $1.6 \pm 0.6$ \\
\hline Parameter & SVG-Diagonal $(n=17)$ \\
\hline Flow during cardioplegia & $110.0 \pm 26.7$ \\
\hline CR cardioplegia & $0.92 \pm 0.18$ \\
\hline Mean TTF flow & $29.4 \pm 17.8$ \\
\hline CR TTF & $2.96 \pm 2.53$ \\
\hline PI & $1.8 \pm 0.5$ \\
\hline Parameter & LIMA-Left anterior descending (20) \\
\hline Flow during cardioplegia & $68.9 \pm 33.0$ \\
\hline CR cardioplegia & $1.33 \pm 0.72$ \\
\hline Mean TTF flow & $49.1 \pm 33.4$ \\
\hline CR TTF & $1.49 \pm 0.86$ \\
\hline PI & $1.6 \pm 0.7$ \\
\hline Parameter & SVG- Left anterior descending $(n=7)$ \\
\hline Flow during cardioplegia & $110.0 \pm 29.4$ \\
\hline CR cardioplegia & $0.98 \pm 0.33$ \\
\hline Mean TTF flow & $39.5 \pm 25.6$ \\
\hline CR TTF & $1.74 \pm 0.88$ \\
\hline PI & $1.5 \pm 0.4$ \\
\hline
\end{tabular}

SVG: saphenous vein graft; LIMA: Left internal thoracic artery; CR: coronary resistances, TTF: transit time flowmetry, PI: pulsatility index. 
When the primary safety endpoint is considered, we did not observe any intraoperative adverse event related to the selective administration of cardioplegia in the venous grafts. When the feasibility endpoint is concerned, TTF has been routinely applied to all mammary artery grafts during cross-clamping time, with recordings coherent to what has been observed in case of venous grafts.

\subsection{Follow-Up Results}

After a mean follow-up of $10.4 \pm 6.0$ months, two patients died (3.2\%) (one for stroke and one for COVID-19-related complications after 7 and 13 months, respectively), 51 were asymptomatic and 10 underwent coronary angiography for onset of angina-like symptoms or instrumental signs of ischemia. Overall, 22 grafts were studied, and occlusion was documented in five $(22.7 \%-4$ saphenous vein grafts and 1 LIMA graft).

When intraoperative flow measurements were retrieved, occluded grafts showed lower flows and higher resistances recorded during aortic cross-clamping, whereas negligible differences could be observed among TTF-derived parameters recorded after withdrawal from CPB (Table 3 and Figure 2).

Table 3. Differences in graft flowmetry and its derivatives between patent and occluded grafts.

\begin{tabular}{cccc}
\hline Parameter & Patent Grafts $(\boldsymbol{n}=\mathbf{1 7})$ & Occluded Grafts $(\boldsymbol{n}=\mathbf{5})$ & $\boldsymbol{p}$ \\
\hline Flow during & $100.2 \pm 27.7$ & $49.2 \pm 31.5$ & 0.0022 \\
cardioplegia & $1.03 \pm 0.33$ & $2.70 \pm 1.57$ & 0.0029 \\
CR cardioplegia & $54.2 \pm 25.5$ & $30.2 \pm 17.1$ & 0.06 \\
Mean TTF flow & $1.74 \pm 0.22$ & $6.38 \pm 9.92$ & 0.09 \\
CR TTF & $1.7 \pm 0.6$ & $2.3 \pm 1.6$ & 0.44 \\
PI &
\end{tabular}

CR: coronary resistances, TTF: transit time flowmetry, PI: pulsatility index.

\section{SVG-OM}

Cardioplegia resistances $0.83(100 \mathrm{mmHg} / 120 \mathrm{~mL} / \mathrm{min})$ TTF - resistances $0.79(65 \mathrm{mmHg} / 82.1 \mathrm{~mL} / \mathrm{min})$

PI 1.1

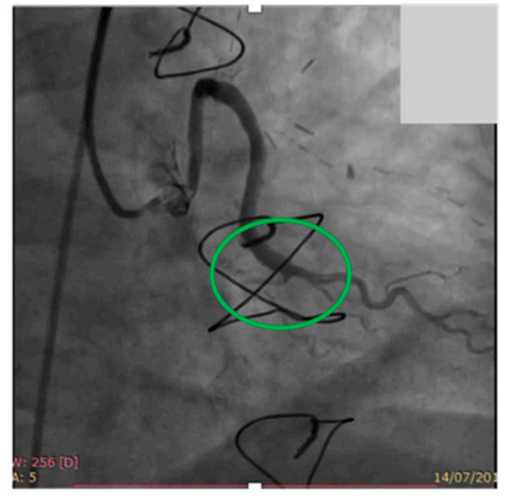

(a)
LIMA-LAD

Resistances $3.54 \quad(92 \mathrm{mmHg} / 26 \mathrm{~mL} / \mathrm{min})$ TTF - resistances 2,11 (65 $\mathrm{mmHg} / 30.8 \mathrm{~mL} / \mathrm{min})$ PI 1.2

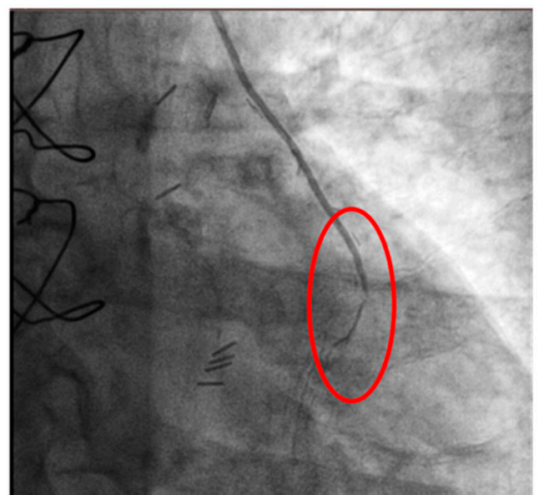

(b)

Figure 2. Examples of coronary angiographic evidence combined with intraoperative flowmetric details (a) patent graft with satisfactory parameters; (b) occluded graft with suboptimal flowmetric values. SVG-OM (saphenous vein graft to obtuse marginal); LIMA-LAD (left internal mammary artery to left anterior descending).

For the univariate logistic regression analysis, only CR-cardioplegia was significantly associated with graft occlusion, (exact OR 25.1, exact 95\% CI 2.06-> 999.99, $p=0.0014$ ) with none of the other recorded or derived parameters reaching statistical significance (Table 4). Interestingly, the risk of graft occlusion increases by 3.8 fold per each 0.5 unit step of CR-cardioplegia. 
Table 4. Univariate logistic regression model to predict graft occlusion.

\begin{tabular}{cccc}
\hline Parameter & OR & $\mathbf{9 5 \% ~ C I ~}$ & $p$ \\
\hline CR cardioplegia & 25.1 & $2.1->999$ & 0.0420 \\
CR TTF & 1.28 & $0.74-2.20$ & 0.37 \\
$\mathrm{TTF}<20 \mathrm{~mL} / \mathrm{min}$ & 1.88 & $0.13-26.2$ & 0.64 \\
$\mathrm{TTF}<31 \mathrm{~mL} / \mathrm{min}$ & 4.88 & $0.59-40.3$ & 0.14 \\
$\mathrm{PI}$ & 1.96 & $0.68-5.64$ & 0.21 \\
$\mathrm{PI}>3$ & 11.78 & $0.11->999$ & 0.23 \\
\hline
\end{tabular}

CR: coronary resistances, TTF: transit time flowmetry, PI: pulsatility index.

\subsection{Discriminant Analysis}

ROC analysis showed that only CR-cardioplegia (AUC 0.9059) demonstrated an adequate discriminatory ability for the prediction of graft failure (Figure 3), being higher than any other compared variable (DeLong test vs. CR-protamine $p=0.0386$; vs. TTF $<20 \mathrm{~mL} / \mathrm{min}$ $p=0.0044$; vs. TTF $<31 \mathrm{~mL} / \min p=0.0449$; vs. PI $>3 p=0.0110)$. We identified $2.0 \mathrm{mmHg} / \mathrm{mL} / \mathrm{min}$ as the most appropriate cut-off, with a sensitivity of $80 \%$ and a specificity of $100 \%$ (Table 5).

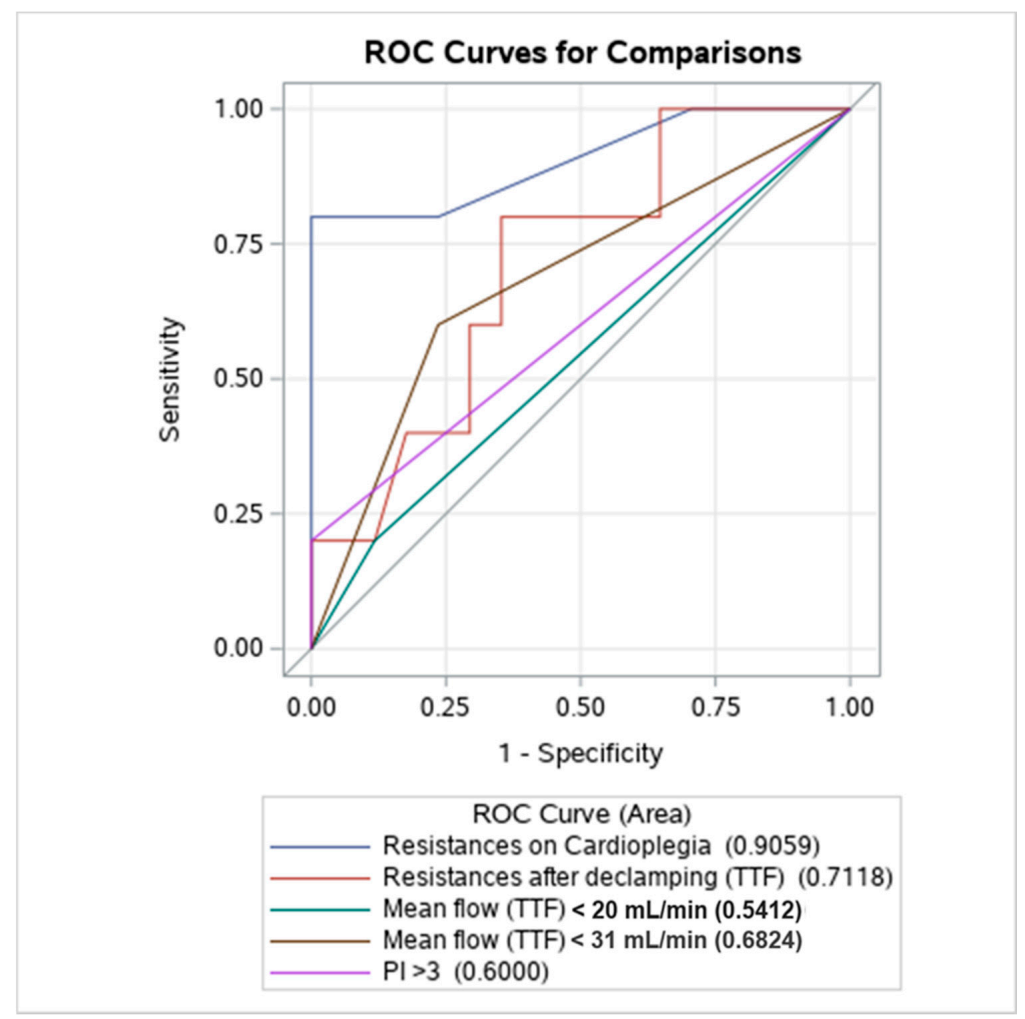

Figure 3. Discriminant ability of different parameters to predict early graft failure. TTF: transit time flowmetry; PI: pulsatility index. ROC (receiver operative characteristic).

Table 5. Bootstrapped cut-off points (with 95\% confidence intervals) of transit time flow derived parameters for predictability of 1-year graft occlusion.

\begin{tabular}{cccc}
\hline Variables & Cut-Off & Sensitivity & Specificity \\
\hline CR cardioplegia & $\geq 2.0(2.0-3.5)$ & $80.0 \%(50.0-100)$ & $100 \%(100-100)$ \\
CR TTF & $\geq 2.03(1.16-24.1)$ & $80.0 \%(50.0-100)$ & $64.7 \%(16.7-100)$ \\
Mean TTF flow & $\leq 51.8(30-51.8)$ & $100 \%(0-100)$ & $58.8 \%(33.3-100)$ \\
\hline
\end{tabular}

CR: coronary resistances, TTF: transit time flowmetry. 


\section{Discussion}

In the present study we observed that coronary resistances can be easily assessed intraoperatively, and can provide useful adjunctive knowledge on the anastomotic graft quality, beside already established technologies, such as TTF. Furthermore, intraoperative assessment of coronary resistances, calculated during aortic cross-clamping time, may predict graft patency at mid-term follow-up.

Intraoperative assessment of graft patency during $\mathrm{CABG}$ is mandatory, as it allows the detection and correction of any graft failure. Among all currently available techniques, TTF is one of the most applied methods. Although its use is supported by current guidelines [1], several authors questioned the reliability of flowmetry and its interpretation, which necessitates the complementary evaluation of flows, flow waveform and its derivatives. Accordingly, D'Ancona and coworkers observed that mean flow alone is not sufficiently reliable, and support its coupling with PI [13]. A general agreement does not exist even on the most reliable cut offs to detect graft failure [14]. Accordingly, Nakajima et al. proposed a mean flow $<20 \mathrm{~mL} / \mathrm{min}$ [4], Balacumaraswami considered $5 \mathrm{~mL} / \mathrm{min}$ unsatisfactory [15]. In the ROOBY trial, TTF $<20$ and PI $\geq 3$ were considered index of low-flow grafts with poor pulsatility. Finally, the GRIIP trial initially used a mean flow of $10 \mathrm{~mL} / \mathrm{min}$ as a cut-off for graft failure [16], but a later retrospective revision identified $31 \mathrm{~mL} / \mathrm{min}$ as a better value [8]. Thus, the absence of a unique interpretation of flow-derived parameters warrants the development of complementary tools. According to the methodology proposed by Belboul and coworkers [5], CR can be easily assessed intraoperatively. Interestingly, CRcardioplegia recorded in our study were lower compared to those reported by Belboul, even when stratified according to the grafted territory. Generally, we record CR-cardioplegia at a standardized perfusion pressure of $100 \mathrm{mmHg}$ to reach an aimed flow of at least $100 \mathrm{~mL} / \mathrm{min}$, whereas Belboul used a maximal pressure of about $60 \mathrm{mmHg}$ and a target flow of $60 \mathrm{~mL} / \mathrm{min}$. Although the desired ratio is 1:1 in both studies, whether the observed differences of $\mathrm{CR}$ during cardioplegic arrest are related to the distinct perfusion pressures or cooling temperature (normothermic in our study vs. $15{ }^{\circ} \mathrm{C}$ in that of Belboul) is still to be determined.

Investigating the $\mathrm{CR}$ during cardioplegic arrest provides several interesting pieces of knowledge for the operating surgeon. Indeed, from a physiological perspective, CR has three components: (1) a basal low resistance in the plegic heart, when vessels are maximally dilated and cannot contract; (2) an added basal resistance when vessels have tone; (3) a supplementary phasic resistance during ventricular contraction [17]. Therefore, an increase in CR in the arrested heart is mainly determined by a technical failure of distal anastomosis and cannot be influenced either by competitive flow or poor distal run-off. Hence, it could be speculated that low CR-cardioplegia might be considered a quality marker of coronary anastomosis, with increased values suggesting graft revision.

Although Belboul and coworkers set the benchmark for the methodology used in the present study, information regarding the late fate of the implanted grafts is missing [5]. To the best of our knowledge, this is the first study recording the coronary resistances beyond a LIMA-LAD anastomosis in the arrested heart and the first also reporting the correlation between coronary resistances and graft failure in the early follow-up. In the randomized ROOBY Trial, Quin and coworkers evidenced how grafts with low intraoperative TTF mean flow $(<20 \mathrm{~mL} / \mathrm{min})$ and high PI $(>3)$ were more often occluded at 1 year follow-up [2]. However, although such cut-offs presented sufficient specificity $(>80 \%)$, sensitivity was poor $($ all $<40 \%)$. A more recent subanalysis of the ROOBY Trial proved that intraoperative TTF assessment of graft patency was associated with a lower likelihood of having an occluded graft at 1 year (29\% vs. 38\% non-TTF, $p=0.01$ ) [18]. Conversely, Hol and colleagues could not demonstrate any correlation between flows and PI in a prospective cohort of grafts with angiography performed at a 1-year follow-up [19]. In our study, the retrospective analysis of intraoperative TTF recordings showed similar mean TTF flow or PI between occluded and patent grafts, whereas only flows and resistances recorded during cardioplegia were meaningfully different. Furthermore, CR-cardioplegia showed the 
highest discriminant ability compared to commonly investigated flow derived parameters. According to our experience, we support routine intraoperative assessment of graft patency, and we believe that adjunctive information, readily available at bedside, might improve the predictability of long-term graft performance. In particular, the discriminant ability of the selected cut-off of $2.0 \mathrm{mmHg} / \mathrm{mL} / \mathrm{min}$ was superior to other parameters, displaying a sensitivity of $80 \%$ and a specificity of $100 \%$.

\section{Limitations}

Our study has several limitations. First, the small number of patients included prevent firm conclusions from being drawn on this topic. Secondly, it has been retrospectively designed. Thirdly, it is not a randomized controlled trial. Finally, some patient-related risk factors (e.g., target vessel size, extension of the disease, adherence to optimal medical therapy) are missing, and thus some intraoperative biases might not have been adequately addressed in our models. Future prospective studies, specifically designed to control all patients with computed tomographic coronary angiography, will allow the inclusion of more patients in the analysis and acquire more details on the predictive power of our index.

Conversely, the single-centre design guarantees the uniformity of data collection and of surgical technique.

\section{Conclusions}

Transit time flowmetry remains the most common method used for the intraoperative assessment of the quality of grafts. Coronary resistances are easy to derive intraoperatively and help to identify graft at potential risk of early failure. We propose the routine recording of coronary resistances during aortic cross-clamping as an additional tool to overcome the acknowledged limitation of TTF to predict graft occlusion at 1 year. LIMA-LAD is not a limitation for measurement during aortic cross-clamping.

Author Contributions: Conceptualization, A.S.R., F.C.; methodology, A.S.R., F.C.; validation, L.M., G.C.; formal analysis, A.S.R., F.C.; data curation, A.L.; writing—original draft preparation, A.S.R., F.C.; writing - review and editing, F.P.; visualization, L.M., G.C., G.V., A.P., B.F.D.D.; supervision, F.P. All authors have read and agreed to the published version of the manuscript.

Funding: This research received no external funding.

Institutional Review Board Statement: The study was conducted according to the guidelines of the Declaration of Helsinki. Ethical review and approval were waived for this study, due to the retrospective nature of the investigation and the lack of experimental intervention.

Informed Consent Statement: Informed consent was obtained from all subjects involved in the study.

Data Availability Statement: Not applicable.

Conflicts of Interest: The authors declare no conflict of interest.

\section{References}

1. Neumann, F.-J.; Sousa-Uva, M.; Ahlsson, A.; Alfonso, F.; Banning, A.P.; Benedetto, U.; Byrne, R.A.; Collet, J.-P.; Falk, V.; Head, S.J.; et al. 2018 ESC/EACTS Guidelines on myocardial revascularization. Russ. J. Cardiol. 2019, 40, 87-165.

2. Quin, J.; Lucke, J.; Hattler, B.; Gupta, S.; Baltz, J.; Bishawi, M.; Almassi, G.H.; Grover, F.L.; Collins, J.; Shroyer, A.L. Surgeon judgment and utility of transit time flow probes in coronary artery bypass grafting surgery. JAMA Surg. 2014, 149, 1182-1187. [CrossRef] [PubMed]

3. Amin, S.; Pinho-Gomes, A.-C.; Taggart, D.P. Relationship of Intraoperative Transit Time Flowmetry Findings to Angiographic Graft Patency at Follow-Up. Ann. Thorac. Surg. 2016, 101, 1996-2006. [CrossRef] [PubMed]

4. Nakajima, H.; Takazawa, A.; Yoshitake, A.; Tochii, M.; Tokunaga, C.; Hayashi, J.; Izumida, H.; Kaneyuki, D.; Asakura, T.; Iguchi, A. Intraoperative transit-time flowmetry in patients undergoing coronary surgery to determine relationships between graft flow and patency and prior coronary interventions and flow demand: A retrospective study. J. Cardiothorac. Surg. 2018, 13, 121. [CrossRef] [PubMed]

5. Belboul, A.; Rådberg, G.; Roberts, D.; Dernevik, L. Intraoperative assessment of coronary flow and coronary vascular resistance during coronary bypass surgery. Scand. Cardiovasc. J. 1999, 33, 23-28. [CrossRef] [PubMed] 
6. Rubino, A.S.; Onorati, F.; Scalas, C.; Serraino, G.F.; Marsico, R.; Gelsomino, S.; Lorusso, R.; Renzulli, A. Intra-aortic balloon pumping recruits graft flow reserve by lowering coronary resistances. Int. J. Cardiol. 2012, 154, 293-298. [CrossRef] [PubMed]

7. Onorati, F.; Santarpino, G.; Rubino, A.; Cristodoro, L.; Scalas, C.; Renzulli, A. Intraoperative bypass graft flow in intra-aortic balloon pump-supported patients: Differences in arterial and venous sequential conduits. J. Thorac. Cardiovasc. Surg. 2009, 138, 54-61. [CrossRef] [PubMed]

8. Une, D.; Deb, S.; Chikazawa, G.; Kommaraju, K.; Tsuneyoshi, H.; Karkhanis, R.; Singh, S.; Vincent, J.; Tsubota, H.; Sever, J.; et al. Cut-off values for transit time flowmetry: Are the revision criteria appropriate? J. Card. Surg. 2013, 28, 3-7. [CrossRef] [PubMed]

9. Di Giammarco, G.; Pano, M.; Cirmeni, S.; Pelini, P.; Vitolla, G.; Di Mauro, M. Predictive value of intraoperative transit-time flow measurement for short-term graft patency in coronary surgery. J. Thorac. Cardiovasc. Surg. 2006, 132, 468-474. [CrossRef] [PubMed]

10. DeLong, E.R.; DeLong, D.M.; Clarke-Pearson, D.L. Comparing the areas under two or more correlated receiver operating characteristic curves: A non- parametric approach. Biometrics 1988, 44, 837-845. [CrossRef] [PubMed]

11. Efron, B.; Tibshirani, R. Bootstrap Methods for Standard Errors, Confidence Intervals, and Other Measures of Statistical Accuracy. Stat. Sci. 1986, 1, 54-75. [CrossRef]

12. R Core Team. R: A Language and Environment for Statistical Computing; R Foundation for Statistical Computing: Vienna, Austria, 2020. Available online: https:/ / www.R-project.org/ (accessed on 26 May 2021).

13. D'Ancona, G.; Karamanoukian, H.L.; Ricci, M.; Schmid, S.; Bergsland, J.; Salerno, T.A. Graft revision after transit time flow measurement in off-pump coronary artery bypass grafting. Eur. J. Cardiothorac. Surg. 2000, 17, 287-293. [CrossRef]

14. Thuijs, D.J.; Bekker, M.W.; Taggart, D.P.; Kappetein, A.P.; Kieser, T.M.; Wendt, D.; Di Giammarco, G.; Trachiotis, G.D.; Puskas, J.D.; Head, S.J. Improving coronary artery bypass grafting: A systematic review and metaanalysis on the impact of adopting transit-time flow measurement. Eur. J. Cardio-Thorac. Surg. 2019, 56, 654-663. [CrossRef] [PubMed]

15. Balacumaraswami, L.; Taggart, D.P. Digital tools to facilitate intraoperative coronary artery bypass graft assessment. Semin. Thorac. Cardiovasc. Surg. 2004, 16, 266-271. [CrossRef] [PubMed]

16. Singh, S.K.; Desai, N.D.; Chikazawa, G.; Tsuneyoshi, H.; Vincent, J.; Zagorski, B.M.; Pen, V.; Moussa, F.; Cohen, G.N.; Christakis, G.T.; et al. The Graft Imaging to Improve Patency (GRIIP) clinical trial results. J. Thorac. Cardiovasc. Surg. 2010, 139, $294-301 . e 1$. [CrossRef] [PubMed]

17. Klocke, F.J. Coronary blood flow in man. Prog. Cardiovasc. Dis. 1976, 19, 117-166. [CrossRef]

18. Quin, J.A.; Noubani, M.; Rove, J.Y.; Krstacic, J.E.; Hattler, B.; Collins, J.F.; Grover, F.L.; Almassi, G.H.; Shroyer, A.L.; Veterans Affairs Randomized On/Off Bypass Follow-up Study (ROOBY-FS) Group. Coronary Artery Bypass Grafting Transit Time Flow Measurement: Graft Patency and Clinical Outcomes. Ann. Thorac. Surg. 2021, 112, 701-707. [CrossRef] [PubMed]

19. Hol, P.K.; Fosse, E.; Mork, B.E.; Lundblad, R.; Rein, K.A.; Lingaas, P.S.; Geiran, O.; Svennevig, J.L.; Tonnessen, T.I.; Nitter-Hauge, S.; et al. Graft control by transit time flow measurement and intraoperative angiography in coronary artery bypass surgery. Hear. Surg. Forum 2001, 4, 254-258. 